\title{
Association between Resistin and High Sensitive Troponin I in St Elevation Myocardial Infarction and Systolic Heart Failure
}

\author{
Trisulo Wasyanto'), Laurent Febrilia²) \\ 1)Department of Cardiology and Vascular Medicine, Faculty of Medicine, \\ Universitas Sebelas Maret/ Dr. Moewardi Hospital, Surakarta \\ ${ }^{2)}$ Department of Cardiology and Vascular Medicine, Faculty of Medicine, \\ Universitas Sebelas Maret
}

\section{ABSTRACT}

Background: Nearly half of all patients with acute myocardial infarction (AMI) have left ventricular systolic dysfunction and one-third have symptoms of heart failure (HF). In patients with AMI the resistin level correlated inversely with left ventricular ejection fraction (LVEF). Increased levels of high sensitive (hs) troponin I are associated with poorer prognosis. This study aimed to determine the association between levels of resistin and hs troponin I in ST elevation myocardial infarction (STEMI) patients with systolic HF.

Subjects and Method: This was a crosssectional study was conducted at Dr. Moewardi General Hospital, Surakarta, from April 1 to May 31, 2018. A sample of 32 patients who admitted which diagnosed with STEMI was selected for this study. They were divided into two group according to result of LVEF measurement, LVEF < 40\% and LVEF $\geq 40 \%$. Blood examination and transthoracic echo-cardiography were performed to all patients. Correlation test using partial and multiple correlation test. To different 2 mean using Mann Whitney test.
Results: Mean of patient age was 59.5 years old. Resistin decreased LVEF $(\mathrm{r}=-0.41 ; \mathrm{p}=$ 0.009), and it was statistically significant. Hs troponin I decreased LVEF $(\mathrm{r}=-0.25 ; \mathrm{p}=$ o.o81), but it was marginally significant. Resistin level and hs troponin I increased LVEF ( $\mathrm{r}=$ $0.47 ; p=0.025$ ), and it statistically significant.

Conclusion: There was an association between resistin and hs troponin I level together in STEMI patients with systolic HF. There was an association of resistin levels in STEM I patients with systolic HF. There was no association of hs troponin I levels in STEMI patients with systolic HF.

Keywords: Resistin, hs troponin I, STEMI, systolic heart failure.

\section{Correspondence:}

Trisulo Wasyanto. Department of Cardiology and Vascular Medicine, Faculty of Medicine, Universitas Sebelas Maret/ Dr. Moewardi Hospital. Jl. Kol. Sutarto 132, Surakarta 57126, Central Java, Indonesia. Email: trisulo.wasyanto@gmail.com.

Cite this as:

Wasyanto T, FebriliaL (2020). Association between Resistin and High Sensitive Troponin I in St Elevation Myocardial Infarction and Systolic Heart Failure.Indones J Med. 5(1): 1-9.

https://doi.org/10.26911/theijmed.2020.05.01.01

cC (i) (2) Indonesian Journal of Medicine is licensed under a Creative Commons

cc)

BACKGROUND

Nearly half of all patients with acute myo-cardial infarction (AMI) experience left ventricular (LV) systolic dysfunction and one third show symptoms of heart failure (HF). Based on ESC/ACCF/AHA, HF can be divi- ded into 3 types namely HF with dec-reased ejection fraction (EF) or systolic $\mathrm{HF}$ $(\mathrm{EF}<40 \%)$; HF with midrange ejection fraction (EF 40-49\%); and HF with good ejection fraction ( $\mathrm{EF} \geq 50 \%$ ) (Ponikowski et al., 2016). Research in ACS patients shows that 
serum resistin levels correlate inversely with the left ventricular ejection fraction (LVEF), thus showing an increase in resistin related to the severity of injury ischemic myocardial (Chu et al., 2008). Other studies suggest that increased serum resistin in ST elevation myocardial infarction (STEMI) pa-tients correlates with major adverse cardiac events (MACE) (Erer et al., 2014).

Resistin plays a role in the development of atherosclerosis as in studies on smooth muscle cell (SMC) and monocytes/ macrophages. Resistin plasma levels have been shown to increase in inflammatory conditions. The expression of mRNA and resistin secretion is triggered by lipopoly saccharide (LPS) and TNF- $\alpha$ in leukocytes involved in the innate and adaptive immune system. At the same time resistin alone increases the inflammatory reaction by increasing proinflammatory cytokine production. Resistin together with other inflammatory cytokines can create changes that support the development of atherosclerosis (Kunnari, 2008). Serum resistin levels are associated with white blood count (WBC) and hsCRP. Resistin can also increase the activation of human endothelial cells by increasing the release of endothelin-1, adhesion cells and matrix metal proteinase which all causes proinflammatory activity and causes plaque instability. It can be said that resistin may play a role in the development of ACS by influencing plaque susceptibility through a series of proinflammatory cells and cytokines (Chu et al., 2008). A meta-analysis data reports that resistin levels correlate with cardiovascular death especially in high risk individuals (Fontana et al., 2015). Inflammatory markers such as interleukin (IL)-6, c reactive protein (CRP) and tumor necrosis factor- $\alpha$ (TNF- $\alpha$ ) are independently correlated with cardiovascular events (Gencer et al., 2016). The direct effect of resistin to the expression of IL- $1 \beta$, IL-6, IL-8 and TNF- $\alpha$, compatible with multi cytokine resistance pathways associated with several risk factors for insulin resistance or low grade inflammation and MACE (Menzaghi et al., 2017). The direct mechanism of resistin to HF was demonstrated in neonatal mice with adenovirus-mediated over expression. In this study resistin resulted in increased sarcomere organization, cell size and protein synthesis in cardiomyocytes, as well as expression of atrial natriuretic factors and myosin heavy chains. The heart requires a high ATP to maintain mechanical function continuously, a decrease in ATP affects the myocardium which directly affects myo-cardial contraction and subsequently causes HF (Doenst et al., 2013).

High sensitivity troponin (hsTn) is recommended to be the standard of exami-nation in the emergency department for patients with chest pain, replacing previous cardiac markers such as myoglobin, CKMB and troponin. This test is substantially more sensitive than the previous test but has low specificity for AMI, because it can detect myocardial injury from various causes (Morrow and Antman, 2009). Increased levels of hs Tn I are associated with a worse prognosis (Bonaca et al., 2010). In the event of an AMI, an increase in hsTn I level will occur, which is a unit that inhibits the troponin complex to associate with thin filaments, and inhibits the actin-myosin interaction of intracellular $\mathrm{Ca} 2+$, where changes in the $\mathrm{Ca} 2+$ role will also result in changes in regulation of myocardial contractility (Layland et al., 2005).

The purpose of this study was to determine the association between resistin levels and hs troponin I in ST elevation myocardial infarction (STEMI) patients with systolic HF.

\section{SUBJECTS AND METHOD}

\section{Study Design}

The study was conducted at the Emergency Room and Intensive Cardiovascular Care 
Unit (ICVCU) at Dr. Moewardi General Hospital Surakarta in STEMI patients. This study uses a cross sectional design.

\section{Population dan Sample}

A total of 32 patients with STEMI who were treated at ICVCU of Dr. Moewardi General Hospital, from 1 April to 31 May 2018, was selected by consecutive sampling.

\section{Study Variables}

The dependent variable in this study was systolic Heart Failure. The independent variable in this study is resistin and high sensitive troponin I

\section{Study Instruments}

The definition of STEMI patients is in accordance with the recommendations of the $\mathrm{Eu}$ ropean Society of Cardiology (ESC) / American College of Cardiology Foundation (ACCF)/American Heart Association (AHA)/ WHO task force (Thygesen et al., 2012). Exclusion Criteria: patients with acute aortic dissection, severe sepsis, malignancy, immuno compromised disorders and patients with chronic kidney disease. Systolic heart failure is defined as a left ventricular ejection fraction (LVEF) <40\% by exami-nation of the GE Vivid 6 brand echocardio-graphy by Simpson's method. Resistin levels were measured by the Elisa method by Prodia clinical laboratories. Hs troponin I levels were measured by Elisa's method by clinical laboratory of Dr. Moewardi hospital.

\section{Data Analysis}

Data analysis was performed using the Mann Whitney test.

\section{Research Ethic}

The research ethics include inside informed consent, identity confidentiality, and ethical clearance carried out in the Dr. Moewardi hospital, Surakarta.

\section{RESULTS}

The study subjects were 32 people with an average age of $59.5 \pm 9.59$ years, divided into two groups, namely the group that had a
LVEF of less than $40 \%$ by 15 people (46.9\%) and the rest were the group that had the same LVEF or greater than $40 \%$ which was 17 people (53.1\%).

The mean age of patients with LVEF $<40 \%(58.47 \pm 8.75)$ was not significantly different from patients with LVEF $\geq 40 \%$ (60.41 $\pm 10.46)$ with $\mathrm{p}=0.576$. There were no significant differrences in the onset of chest pain, urea, creatinine, total cholesterol, LDL cholesterol, HDL cholesterol, triglycerides and HbA1c in patients with LVEF $<40 \%$ and $\mathrm{LVEF} \geq 40 \%$.

The results of homogeneity testing of characteristic variables that are quantitative found that all of these characteristic variables are homogeneous. Testing the relationship of resistin and hs troponin I to the LVEF that shows systolic HF is done by correlation analysis, both partial correlation and a multiple correlation. Description and Test Results Homogeneity of quantitative varia-bles of demographic and clinical characteris-tics in this study is in Table 3.

Resistin was negatively correlated with LVEF ( $\mathrm{r}=-0.41 ; \mathrm{p}=0.009$ ), and it was statistically significant. This means, if the resistin level is high, then there is a tendency for a significant decrease in LVEF and vice versa if the resistin is low then the LVEF will increase significantly. Hs troponin I was negatively correlated with LVEF $(r=-0.25$; $\mathrm{p}=0.081$ ), and it was marginally significant. This means, if the hs troponin I level is high or low there is no tendency to significantly increase or decrease LVEF. Resistin level and hs troponin I positively correlated with LVEF ( $\mathrm{r}=0.47 ; \mathrm{p}=0.025$ ), and it was statistically significant. This means, if the levels of resis-tin and hs troponin I together are low or high then there will be a tendency for LVEF to increase or decrease significantly.

Table 3 showed the difference of 2 mean test of resistin and $\mathrm{Hs}$ troponin in LVEF $<40 \%$ and LVEF $\geq 40 \%$. Mean resistin 
Wasyanto T et al./ Association between Resistin and High Sensitive

level in LVEF <40\% (Mean= 27.81; $\mathrm{SD}=$ 16.99) was higher than LVEF $\geq 40 \%$ (Mean= 9.38; $\mathrm{SD}=5.44$ ), and it was statistically significant $(\mathrm{p}=0.001)$. Hs Troponin $\mathrm{I}$ in LVEF <40\% (Mean= 8833.25; SD=9260.12) was higher than LVEF $\geq 40 \%$ (Mean= 4923.58; $\mathrm{SD}=7601.43)$, but it was statistically non-significant $(\mathrm{p}=0142)$. Table 3 showed the difference of 2 mean test of resistin and
Hs troponin in LVEF $<40 \%$ and LVEF $\geq$ 40\%. Mean resistin level in LVEF <40\% (Mean $=27.81 ; \mathrm{SD}=16.99)$ was higher than $\mathrm{LVEF} \geq 40 \%(\mathrm{Mean}=9.38 ; \mathrm{SD}=5.44)$, and it was statistically significant $(\mathrm{p}=0.001)$. Hs Troponin I in LVEF <40\% (Mean= 8833.25; $\mathrm{SD}=9260.12$ ) was higher than $\mathrm{LVEF} \geq 40 \%$ (Mean= 4923.58; $\mathrm{SD}=7601.43)$, but it was statistically non-significant $(\mathrm{p}=0142)$.

Table 1. Comparison of Variable Characteristics of Left Ventricular Ejection Faction Group $<\mathbf{4 0 \%}$ and Group $\geq 40 \%$.

\begin{tabular}{|c|c|c|c|c|c|c|}
\hline \multirow{2}{*}{ Variable } & \multicolumn{2}{|c|}{ LVEF $<40 \%$} & \multicolumn{2}{|c|}{ LVEF $\geq 40 \%$} & \multirow[t]{2}{*}{ OR } & \multirow[t]{2}{*}{$\mathbf{p}$} \\
\hline & $\mathbf{N}$ & $\%$ & $\mathbf{N}$ & $\%$ & & \\
\hline \multicolumn{7}{|l|}{ Gender } \\
\hline a. Male & 11 & $73 \cdot 3$ & 13 & 76.5 & \multirow{2}{*}{0.04} & \multirow{2}{*}{0.838} \\
\hline b. Female & 4 & 26.7 & 4 & 23.4 & & \\
\hline \multicolumn{7}{|l|}{ STEMI type } \\
\hline a. Anteroseptal & 2 & 13.3 & 2 & 11.8 & \multirow{7}{*}{6.69} & \multirow{7}{*}{0.351} \\
\hline b. Anterior & 2 & $13 \cdot 3$ & 5 & 29.4 & & \\
\hline c. Anterior extensive & 5 & $33 \cdot 3$ & 3 & 17.6 & & \\
\hline d. Inferior & 3 & 20.0 & 3 & 17.6 & & \\
\hline e. Inferoposterior & 1 & 6.7 & 1 & $5 \cdot 9$ & & \\
\hline f. Inferior RV & $\mathrm{O}$ & 0.0 & 3 & 17.6 & & \\
\hline g. Inferoposterior RV & 2 & 13.3 & 0 & $\mathrm{O}$ & & \\
\hline \multicolumn{7}{|l|}{ Early Killip Class } \\
\hline a. I & 8 & $53 \cdot 3$ & 12 & 70.6 & \multirow{3}{*}{1.08} & \multirow{3}{*}{0.583} \\
\hline b. II & 6 & 40.0 & 4 & 23.5 & & \\
\hline c. IV & 1 & 6.7 & 1 & 5.9 & & \\
\hline \multicolumn{7}{|l|}{$\mathrm{DM}$} \\
\hline a. DM & 6 & 40.0 & 6 & $35 \cdot 3$ & \multirow{2}{*}{0.08} & \multirow{2}{*}{0.784} \\
\hline b. Non DM & 9 & 60.0 & 11 & 64.7 & & \\
\hline \multicolumn{7}{|l|}{ History of Hypertension } \\
\hline a. Hypertension & 10 & 66.7 & 6 & $35 \cdot 3$ & \multirow{2}{*}{3.14} & \multirow{2}{*}{0.077} \\
\hline b. No hypertension & 5 & $33 \cdot 3$ & 11 & 64.7 & & \\
\hline \multicolumn{7}{|l|}{ Smoker status } \\
\hline a. Smoker & 5 & $33 \cdot 3$ & 10 & 58.8 & \multirow{2}{*}{2.08} & \multirow{2}{*}{0.149} \\
\hline b. Non smoker & 10 & 66.7 & 7 & 41.2 & & \\
\hline \multicolumn{7}{|l|}{ History of Dyslipidemia } \\
\hline a. Yes & 5 & $33 \cdot 3$ & 4 & 23.5 & \multirow{3}{*}{0.38} & \multirow{2}{*}{0.538} \\
\hline b. No Dyslipidemia & 10 & 66.7 & 13 & 76.5 & & \\
\hline \multicolumn{6}{|l|}{ Worsening Killip } & \\
\hline a. Yes & 3 & 20.0 & 2 & 11.8 & 0.41 & 0,522 \\
\hline b. No & 9 & 80.0 & 15 & 88.2 & 0.41 & 0.522 \\
\hline Death Event & & & & & & \\
\hline a. Yes & 4 & 26.7 & 2 & 11.8 & 1.16 & 0281 \\
\hline b. No & 11 & $73 \cdot 3$ & 15 & 88.2 & 1.10 & 0.281 \\
\hline Arrhythmias & & & & & & \\
\hline a. Yes & 6 & 40.0 & 3 & 17.6 & 1.97 & 0.160 \\
\hline b. No & 9 & 60.0 & 14 & 82.4 & 1.97 & 0.100 \\
\hline
\end{tabular}


Wasyanto T et al./ Association between Resistin and High Sensitive

Table 2. Results of Correlation Analysis of Resistin and Hs Troponin I Variables with Left Ventricular Ejection Fraction

\begin{tabular}{lcc}
\hline \multicolumn{1}{c}{ Independent Variables } & $\mathbf{r}$ & $\mathbf{p}$ \\
\hline Resistin & -0.41 & 0.009 \\
Hs Troponin I & -0.25 & 0.081 \\
Resistin and Hs Troponin I & 0.47 & 0.025 \\
\hline
\end{tabular}

Table 3. Difference 2 Mean Test of Resistin and Hs Troponin Variable in LVEF $<40 \%$ and $L V E F \geq 40 \%$

\begin{tabular}{lccccc}
\hline \multirow{2}{*}{ Variable } & \multicolumn{2}{c}{ LVEF $<40 \%(\mathbf{4 0} \%)$} & \multicolumn{2}{c}{ LVEF $\geq \mathbf{4 0 \%}(\mathbf{n}=\mathbf{1 7})$} & \multirow{2}{*}{$\mathbf{p}$} \\
\cline { 2 - 5 } & Mean & SD & Mean & SD & \\
\hline Resistin & 27.81 & 16.99 & 9.38 & 5.44 & 0.001 \\
Hs Troponin I & 8833.25 & 9260.12 & 4923.58 & 7601.43 & 0.142 \\
\hline
\end{tabular}

Tabel 4. Results of Correlation Analysis of Sample Characteristics on Resistin and Hs Troponin I

\begin{tabular}{lcccc}
\hline \multirow{2}{*}{ Independent Variables } & \multicolumn{2}{c}{ Resistin } & \multicolumn{2}{c}{ Hs Troponin I } \\
\cline { 2 - 5 } & $\mathbf{r}$ & $\mathbf{p}$ & $\mathbf{r}$ & $\mathbf{p}$ \\
\hline Gender & 0.01 & 0.991 & -0.24 & 0.810 \\
Smoker status & 1.89 & 0.068 & 0.38 & 0.708 \\
History of hypertension & 1.68 & 0.104 & 0.07 & 0.945 \\
DM & -1.05 & 0.303 & 0.92 & 0.385 \\
Azotemia & 1.52 & 0.139 & 0.88 & 0.385 \\
Dyslipidemia & 0.47 & 0.646 & 1.49 & 0.147 \\
Early Killip Class & 0.17 & 0.848 & 6.15 & 0.006 \\
STEMI type & 2.79 & 0.032 & 0.78 & 0.594 \\
Arrhythmia Events & 0.80 & 0.433 & -0.20 & 0.844 \\
Death Events & 3.35 & 0.002 & 1.24 & 0.225 \\
Worse Class Killip & 1.36 & 0.186 & -0.14 & 0.890 \\
\hline
\end{tabular}

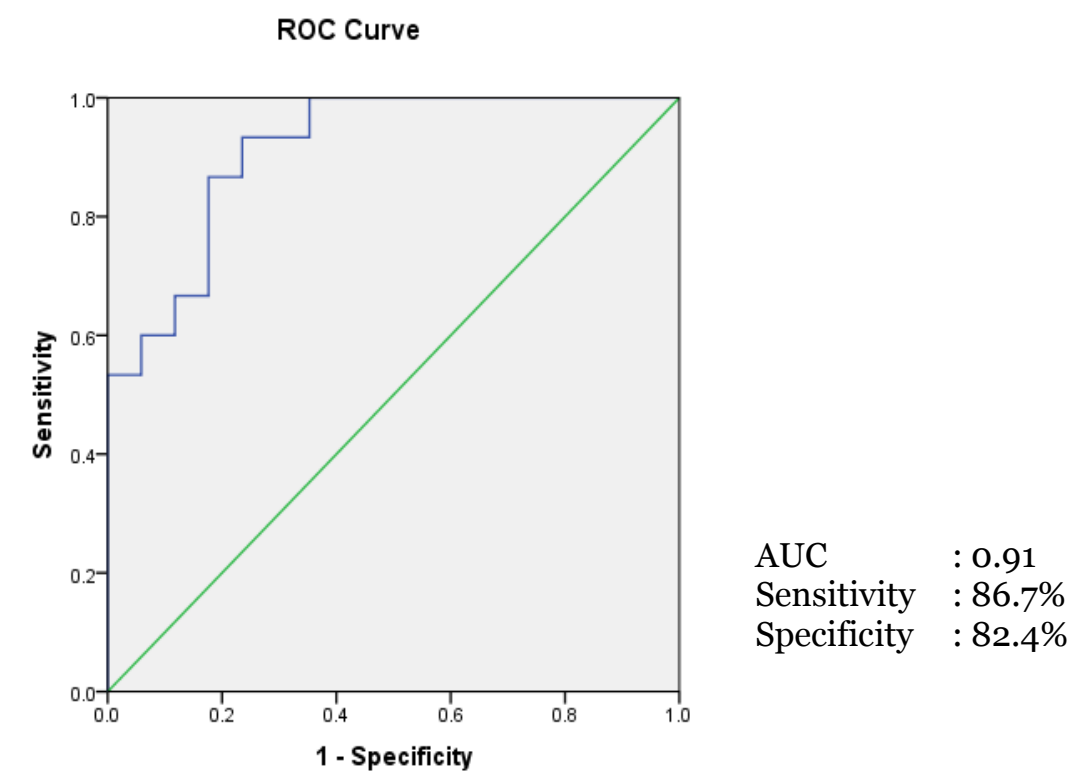

Figure 1. ROC Analysis of Resistin for Systolic Heart Failure 
The ROC curve generated from the resistin variable for the identification of systolic HF resulted in an Area under Curve (AUC) value of 0.914 or included in the excellent category. It can be interpreted that the resistin variable identifies very well the incidence of systolic HF based on the LVEF variable benchmarks. Based on the ROC curve, the Cut of Point value of the resistin variable is $11.74 \mathrm{ng} / \mathrm{mL}$ with a cut of point of the resistin variable of 11.74 $\mathrm{ng} / \mathrm{mL}$, the systolic heart failure event can be identified from the resistin variable having a sensitivity level of $86.7 \%$ with a specificity level of $82.4 \%$ and an accuracy rate of $84.4 \%$.
Meanwhile the ROC curve generated from the hs troponin I variable for identification of systolic HF resulted in an Area under Curve (AUC) value of 0.66 or included in the weak category. It can be interpreted that hs troponin I variable is weak in identifying systolic HF based on the LVEF variable benchmark. Based on the ROC curve, the Cut of Point value of the Hs troponin I variable is $5,124.50 \mathrm{ng} / \mathrm{L}$. With the cut of point of the Hs troponin I variable of 5,124.50 ng/L, the systolic heart failure can be identified from the Hs troponin I variable has a sensitivity level of $60.0 \%$ with a specificity level of $76.5 \%$ and an accuracy rate of $68.7 \%$.

ROC Curve

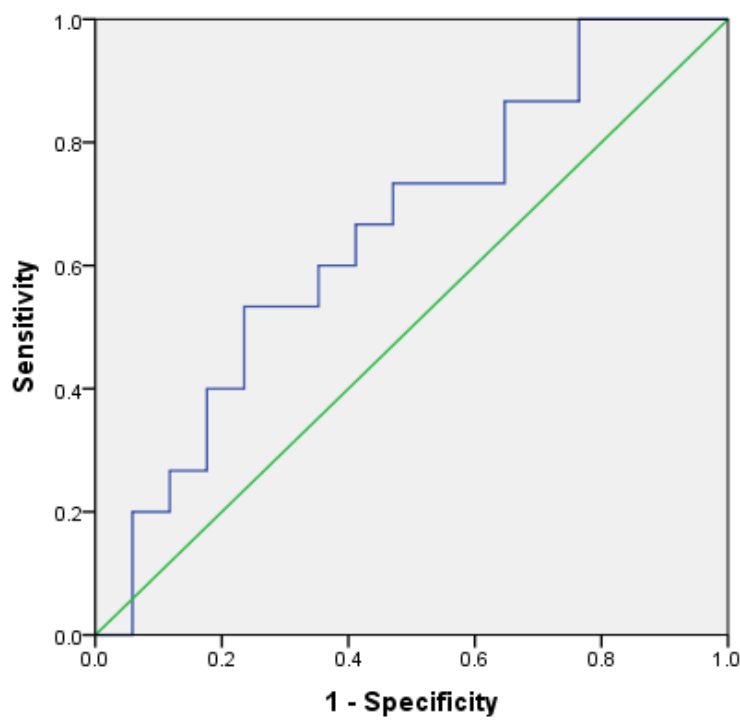

AUC $\quad: 0.66$

Sensitivity : $60.0 \%$

Specificity $: 76.5 \%$

Figure 2. ROC Analysis of Troponin I against Systolic Heart Failure

In this study, HF patients were divided into two groups, namely $\mathrm{HF}$ patients with LVEF <40\% categorized as systolic HF and HF patients with LVEF $\geq 40 \%$. In a large sample study, the Immediate Myocardial Metabolic Enhancement during Initial Assessment and Treatment in Emergency care (IMMEDIATE) Trial in 2016, stated that there were signifi-cant differences in post ACS patients with LVEF $<40 \%$ and had a 1-year mortality rate or HF hospitalization higher than patients with LVEF> 40\% (Mukherjeeet al., 2016). The results of this study indicate that the level of resistin and LVEF has a significant negative correlation at a significance level of $5 \%(\mathrm{p}<0.05)$ with a correlation value of $\mathrm{r}=-0.414$. This means, if the level of resistin increases then 
there is a tendency for a significant decrease in LVEF and vice versa if the value of resistin is low then the LVEF will experience a significant increase. There was a significant difference in resistin levels in LVEF $<40 \%$ with LVEF $\geq 40 \%$ with $p$ $<0.001$. The results of this study are consistent with previous studies that serum resistin levels are inversely correlated with LVEF, so that an increase in resistin levels correlates with the severity of myocardial ischemic in ACS patients (Chu et al., 2008).

Hs troponin I decreased LVEF, but it was statistically non-significant $(\mathrm{r}=-0.25$; $\mathrm{p}>0.05$ ). In addition, there was no differ-rence between Hs troponin I levels in LVEF $<40 \%$ or with LVEF $\geq 40 \%$ with $\mathrm{p}=0.142$. The possibility of this result could be due to Troponin I level had a peak time of around 12 hours and subsequently decreased, where-as patients who come to the emergency room have different onset of STEMI event (Maha-jan and Jarolim, 2011).

Combination of resistin and Hs troponin I increased LVEF and it was statistically significant $(\mathrm{r}=0.47 ; \mathrm{p}<0.05)$.

By using the ROC curve method, it was found that the level of resistin for the identification of systolic $\mathrm{HF}$ resulted in an Area under Curve (AUC) value of 0.914 or included in the excellent category. Based on the ROC curve, the cut of point value is $11.74 \mathrm{ng} / \mathrm{mL}$. With the cut of point level of resistin of $11.74 \mathrm{ng} / \mathrm{mL}$, the incidence of systolic HF can be identified from the resistin level which has a sensitivity level of $86.7 \%$ and a specificity level of $82.4 \%$, and an accuracy rate of $84.4 \%$; better when compared to Hs troponin I level which has a sensitivity level of $60 \%$ and specificity of $76.5 \%$, and an accuracy rate of only $68.7 \%$. The results of this study indicate that if there are 100 STEMI patients with resistin levels $>11.74 \mathrm{ng} / \mathrm{mL}, 91$ of them are predicted to experi-encesystolic HF.
In this study, resistin levels were related to the extent of infarction in STEMI patients. These results are consistent with research conducted by Zhang et al., that increased serum resistin levels are related to the severity of coronary heart disease (Zhang et al, 2017). The results of this study also showed that resistin levels were associated with death in STEMI patients $(\mathrm{p}=$ 0.002). This is also consistent with the results of other researchers, that resistin levels is correlated with MACE events where one of them is cardiovascular death (Menzaghi et al., 2017; Fontana et al., 2015; Erer et al., 2014).

Based on the results of this study, it can conclude that there is a correlation between resistin and hs troponin I level in STEMI patients with systolic HF. There is a correla-tion between resistin levels in STEMI suffer-ers with systolic HF. There is no correlation between hs troponin level in STEMI sufferers with systolic HF. Resistin levels have a prog-nostic value for the occurrence of systolic HF in STEMI patients with better sensitivity, specificity, and accuracy than hs troponin I levels.

\section{AUTHOR CONTRIBUTION}

Trisulo Wasyanto and Laurent Febrilia collected the data, measured resistin level, examined clinical changes, did data analysis, and wrote the manuscript.

\section{CONFLICT OF INTEREST}

The authors declare there is no conflict of interest.

FUNDING AND SPONSORSHIP

No external funding and sponsorship.

\section{ACKNOWLEDGEMENT}

We would like to thank to Dr. Moewardi Hospital that give permission to collect the data. 


\section{REFERENCE}

Bonaca M, Scirica B, Sabatine M, Dalby A, Spinar J, Murphy SA, et al (2010). Pro-spective evaluation of the prognostic implications of improved assay perfor-mance with a sensitive assay for cardiac Troponin I. J Am Coll Cardiol. 55: 21-18-25. doi: 10.1016/j.jacc-.2010.01.0-4-4.

Chu S, Ding W, Li K, Pang Y, Tang C (2008). Plasma resistin associated with myo-cardium injury in patients with acute coronary syndrome. Circ J. 72: $1249-53$.

Doenst T, Nguyen TD, Abel ED (2013). Cardiac Metabolism in Heart FailureImplications beyond ATP production. Circulation. 113(6): 709-24. doi: 10.11-61/CIRCRESAHA.113.300376.

Erer HB, Sayar N, Guvenc TS, Aksaray S, Yilmaz H, Altay S, Turer A, Oz TK, et al. (2014). Prognostic Value of Serum Resistin Levels in Patients with Acute Myocardial Infarction. Kardiol Pol. 72-(2): 181-6. doi: 10.5603/K-P.a2013.-0086.

Fontana A, Spadaro S, Copetti M, Spoto B, Salvemini L, Pizzini P, et al. (2015). Association between resistin levels and all cause and cardiovascular mortality: A new study and a systematic review and meta-analysis. Plos One. 10(3): E0120419. doi: 10.1371/journal.pone.-01-20419.

Gencer B, Auer R, Rekeneire N, et al. (2016). Association between resistin levels and cardiovascular disease events in older adults: the health, aging and body composition study. $\mathrm{J}$ Atherosclerosis. (245): 181-186. doi:10.1016/j.atheros-clerosis.2015.12 .004 .

Kunnari A (2008). Genetic, Epidemiological and Cell Culture Studies on $\mathrm{Hu}-$ man Resistin. http://herkules.o-ulu.- fi/is-bn-9789514289477/.

Layland J, Solaro RJ, Shah AM (2005). Regulation of cardiac contractile function by troponin I phosphorylation. Cardiovasc Res. 66(1): 12-21. Doi: https://doi.org/10.1016/j.cardiores.2004.12.022.

Mahajan VS, Jarolim P (2011). How to Interpret elevated cardiac troponin levels. Circulation, 124(21): 2350-4. https://doi.org/10.1161/CIRCULATIONAHA.111.023697

Menzaghi C, Marucci A, Antonucci A, De Bonis C, Moreno LO, Salvemini L, et al (2017). Suggestive evidence of a multi-cytokine resistin pathway in humans and its role on cardiovascular events in high-risk individuals. Nature. 7: 44337. Doi: 10.1038/srep44337.

Morrow DA, Antman EM (2009). Evaluation of high-sensitivity assays for cardiac troponin. Clin Chem. 55(1): 58. doi: 10.1373/clinchem.2008.117218 Mukherjee JT, Beshansky JR, Ruthazer R, Alkofide H, Ray M, Kent D, Manning WJ, Huggins GS, Selker HP (2016). In hospital measurement of left ventricular ejection fraction and one year outcomes in acute coronary syndromes: Results from The IMMEDIATE Trial. Cardiovasc Ultrasound. 14(1): 29. doi: 10.1186/s12947-016-0068-1.

Ponikowski P, Voors AA, Anker SD, Bueno H, Cleland JGF, Coats AJS, Falk V, Gon-zález-Juanatey JR, et al. (2016). 2016 ESC guidelines for the diagnosis and treatment of acute and chronic heart failure: The task force for the diagnosis and treatment of acute and chronic heart failure of the European society of cardiology (ESC) developed with the special contribution of the Heart Failure Association (HFA) of the ESC. Eur Heart J. 37(27): 2129- 
Wasyanto T et al./ Association between Resistin and High Sensitive

2200. doi: 10.1093/eurheartj/ehw128

Thygesen K, Alpert JS, Jaffe AS, Simoons ML, Chaitman BR, White HD (2012). Third universal definition of myocardial in-farction. J Am Coll Cardiol. 60: 1581-9. https://doi.org/10.1161/CIR.obo-13e3-1-826e1058.
Zhang YX, Li YX, Yu L, Zhou L (2017). Asso-ciation between serum resistin concen-tration and hypertension: A systematic review and meta-analysis. Oncotarget. 8(25): 41529-37. doi: 10.18632-/onco-target.17561 